\title{
Debiasing Overconfidence among Indonesian Undergraduate Students in the Biology Classroom: An Intervention Study of the KAAR Model
}

\author{
Ai Nurlaelasari Rusmana \\ Division of Science Education, Kangwon National University, \\ 1 Gangwondaehakgil, Chuncheon-si, Gangwon-do, 24341, Republic of Korea \\ ainurlaelasarirusmana@gmail.com
}

\author{
Fenny Roshayanti \\ Department of Science Education, Postgraduate School, \\ Universitas PGRI Semarang, \\ Sidodadi Timur no. 24, Karangtempel, Semarang, 50232, Indonesia \\ fennyroshayanti@upgris.ac.id
}

\begin{abstract}
Minsu Ha
Corresponding author Division of Science Education, Kangwon National University, 1 Gangwondaehakgil, Chuncheon-si, Gangwon-do, 24341, Republic of Korea msha@kangwon.ac.kr
\end{abstract}

Received: 11 February 2020 | Revised:14 April 2020, 2 May 2020 | Accepted: 19 May 2020

\begin{abstract}
Metacognitive ability is enormously important for improving students' learning performance. However, overconfidence bias may hinder students' metacognition abilities. Therefore, in this study, we conducted an intervention to reduce or debias overconfidence among students using the KAAR (knowledge, awareness, action, and reflection) model. Ninety Indonesian undergraduate students were subjects of this study. Overconfidence scores were analyzed using paired sample t-tests in spss to compare the mean difference between pre- and post-tests. Next, their overconfidence patterns during the intervention were analyzed using $\mathrm{R}$ to perform group-based trajectory modeling (GBTM). Two main findings were noteworthy: Watching a video about overconfidence is likely the most significant activity of KAAR model in reducing students'


overconfidence, and, based on students' overconfidence change during the intervention, trajectory analysis classified them into five groups. Recommendations for future intervention studies to reduce overconfidence among students are discussed.

\section{Keywords}

intervention - KAAR model - overconfidence debiasing - undergraduate

\section{Introduction}

During the learning process, the ability to accurately evaluate self-capacity of learning - recognize what is known and pinpoint what is not knownmakes students create better strategies for their learning (Foster, Was, Dunlosky, \& Isaacson, 2017). They can focus on materials they do not understand rather than spend too much time learning things they already know. This is called effective learning. Accordingly, the metacognitive ability becomes tremendously important as it enables students to improve their learning effectiveness (Destan \& Roebers, 2015; White \& Frederiksen, 1998) and will thereby escalate their performance. According to Schraw, Wise, and Roos (2000), with high metacognitive ability, students know better how they can learn a concept more efficiently, process information more comprehensively, and monitor and reflect on their learning performance more accurately.

However, metacognitive ability cannot be easily improved (Nietfeld, Cao, \& Osborne, 2005). In the cognitive process, two types of thinking might occur: Type 1, intuitive thinking, which works automatically, is fast, and happens in an unconscious way, and Type 2 , reflective thinking, which is performed in a controlled, slow, and conscious way (Kahneman, 2003, 2011). Unfortunately, Type 1 thinking unconsciously dominates Type 2 in human thought and becomes the obstacle for metacognition. Type 1 thinking, which involves more impressions, feelings, and intentions, is more likely to generate many kinds of cognitive biases and lead us to cognitive failure. One of the most powerful and significant cognitive biases is overconfidence (Kahneman, 2011). Illustrated in the Dunning-Kruger effect, overconfidence is a bias of thinking where one overestimates one's own performance and tends to not be aware of one's poor performance (Dunning, 2011; Dunning, Johnson, Ehrlinger, \& Kruger, 2003; Kruger \& Dunning, 1999).

Overconfidence occurs when people are utterly sure that what they are thinking is right, while in reality it is not. For example, when overconfident 
students were asked to estimate their exam scores in relation to their peers, their estimated scores exceeded their actual scores, and some even underestimated their peers' scores (Dunning et al., 2003). Some researchers (Neuman, Rafferty, \& Griffiths, 2014; Visé \& Schneider, 2000) have argued that overestimation is partially due to the motivational factors of individuals' wishful thinking and eagerness to achieve their goals. Without a doubt, wishful thinkers tend to be overconfident (Caplin \& Leahy, 2019) as they have difficulties in differentiating between their wishes and their ability to achieve those wishes. Furthermore, according to Myers (1998), the fact that students underestimate their peers' scores is due to the subjective and social desirability to be seen as better than the average. A lack of knowledge and ability to reflect self-capacity also leads people to make estimations based on their feelings, which is how Type 1 thinking works; therefore, they have ineffective self-regulation and poor monitoring skills (Kahneman, 2011). As control and regulation are essential components of metacognitive ability, unrealistic and excessive confidence can substantially hinder efficient metacognition (Destan \& Roebers, 2015). Rather than "knowing what they know," overconfident people are prone to "not knowing what they know" and have no idea of what they do not know.

Ineffective control and regulation will produce an inaccurate self-evaluation. Some studies have found that overconfidence misleads students about their performance in the classroom (Foster et al., 2017; Serra \& DeMarree, 2016). When students think they understand the learning materials but actually do not understand them, they will not gain as much knowledge or experience during the learning process as students who are reflective. This is because overconfident students tend to be less skeptical (Burton, 2008), ignore feedback, and study less or even stop studying (Dunlosky \& Rawson, 2012). This condition is extremely unfavorable for students' academic achievement (Erat, Haluk, \& Demirkol, 2016), as it leads to poor performance (Destan \& Roebers, 2015; Labuhn, Zimmerman, \& Hasselhorn, 2010). To prevent such detrimental consequences, overconfidence bias among students should be reduced.

Recently, some studies concerning overconfidence in science teaching and learning have been published (Mathabathe, 2019; Rachmatullah \& Ha, 2019; Sheldrake, 2016). These studies urged the importance of reducing overconfidence among students in science teaching and learning. Rachmatullah and $\mathrm{Ha}$ (2019) have suggested that science education could be a solution to reducing the students' overconfidence bias. When learning science, students engage in scientific thinking that is empirical, rational, and skeptical, which can avoid biases (Gasparatou, 2017). Mathabathe (2019) added that science instruction could be more focused on encouraging self-regulatory skills to prevent students' learning failures because of overconfidence bias. Further, correcting the bias in the science classroom can be carried out not only by students but also 
by educators and peers (Rachmatullah \& Ha, 2019; Sheldrake, 2016). In reference to those studies, we conducted a study on removing student overconfidence bias in the classroom.

This study was conducted in Indonesia, where the previous study found a crucial issue of overconfidence bias among Indonesian students (Rachmatullah \& Ha, 2019). In their study, Indonesian students showed more robust overconfidence than South Korean students did. Kitsantas, Ware, and Cheema (2010) argued that developing countries, including Indonesia, tend to show higher overconfidence than developed countries. In addition, Stankov and Lee (2014), who studied overconfidence bias across 33 countries, also found that Southeast Asian people had lower accuracy on tests than East Asian people did. Therefore, based on these findings, reducing overconfidence bias may be a way to improve Indonesian students' accuracy and science performance.

\section{Theoretical Framework of KAAR Intervention Model for Overconfidence Debiasing}

In this section, we review relevant works of literature that will be the guiding theoretical framework of the development of our intervention model for overconfidence debiasing. Accordingly, we reviewed some classroom studies on reducing overconfidence in psychology course (Bol \& Hacker, 20o1; Foster et al., 2017; Hacker, Bol, Horgan, \& Rakow, 200o; Hacker, Bol, \& Bahbahani, 2008; Miller \& Geraci, 2011; Nietfeld, Cao, \& Osborne, 2006). In general, there are two approaches for overconfidence debiasing: intervention designed and experience based. Intervention studies rely on the role of a set of activities leading the students to avoid or reduce biased thinking, while experience-based approaches depend on ample experience of taking exams to reduce the bias.

For the current study, we focused on conducting an intervention to lessen the overconfidence bias, given that relying on past experiences has been shown not to help people recognize their own biases (Kahneman, Lovallo, \& Sibony, 2011). Because bias is produced by Type 1 thinking (which is fast and unconscious), people tend to have difficulties catching themselves when they make intuitive errors (Kahneman, 2003; Kahneman et al., 2011). People's inability to sense their own bias makes them unable to debias themselves; therefore, a set of activities in the intervention can be a good mechanism with which to tackle this issue.

In this study, we used the knowledge, awareness, action, and reflection (KAAR) intervention model, which indicates the phases of the cognitive debiasing process. The following is a brief description of each of the phases of the KAAR model. 


\subsection{Knowledge}

The first step of overconfidence debiasing is knowing about the overconfidence itself. Knowing about the existence of bias is a meta-strategy for debiasing (Aczel et al., 2015; Babcock \& Loewenstein, 1997). Knowledge of overconfidence bias, including its causes and the danger it poses to academic performance, should be an initial caution for students to avoid such bias. Education tends to greatly encourage students' confidence in the classroom, because confidence is seen as having positive outcomes on learning goals (Bandura, 1997). However, students receive little warning that being overly confident is detrimental. When students do not know that overconfidence is a negative personality trait, they will keep justifying this bias. It could be harmful to their thinking processes and bring severe pitfalls to their learning endeavors. Fischhoff (1982) has proposed that the first procedure of debiasing is teaching people about bias. Therefore, introducing the presence of overconfidence and providing basic knowledge about overconfidence is the first compulsory step. Understanding overconfidence can lead to the next stage of debiasing: building and raising awareness of bias.

\section{$2.2 \quad$ Awareness}

Some studies have highlighted the importance of awareness in diminishing cognitive bias (Croskerry, Singhal, \& Mamede, 2013; Mair, Shepperd, \& Jørgensen, 2014; Morewedge et al., 2015; Shepperd, Mair, \& Jørgensen, 2018). Even though awareness is a subsequent phase of knowledge, being aware of the cognitive bias differs from knowing the bias itself. Knowing is limited to the understanding of the presence of overconfidence bias and its negative effects, while building awareness of overconfidence bias requires that individuals put in far more thought and self-questioning to determine whether they have a potential bias. Self-questioning involves conscious and in-depth thought about their possible biases in past experience. Remembering past experiences of overconfidence bias may cause a serious impact that can lead students to become more aware of the pitfalls of excessive confidence and to subsequently become less confident (van Geene et al., 2016). In addition, knowing the rules, procedures, and strategies to overcome overconfidence bias can raise students' awareness for overconfidence debiasing (Croskerry et al., 2013).

\subsection{Action}

Being aware of having the bias is not enough to overcome cognitive bias (Fishchoff, 1982; Kahneman et al., 2011; Shepperd et al., 2018). Kahneman et al.'s (2011) study further emphasized that taking the initiative is the essential phase of debiasing. Croskerry et al. (2013) explained that taking action relies on 
individuals' motivation for change. Although students have known and been aware of having overconfidence bias, they must have the willingness to debias their overconfidence. Taking action for debiasing can be more challenging if students cannot recognize their overconfidence when it occurs, thus believing that they do not require any change. Therefore, taking steps to counteract the overconfidence bias is not limited only to individual action but also includes collective action. If we have an obstacle to control bias in our own Type 1 thinking (i.e., when and how it happens), we can apply other people's rational thoughts to correct our erroneous thinking (Camerer \& Hogarth, 1999; Kahneman et al., 2011; Scopelliti et al., 2015). In short, we can use other people's Type 2 thinking to spot biases in our Type 1 thinking. This idea expresses the importance of group activities for cognitive debiasing.

\subsection{Reflection}

One fundamental way to counteract cognitive bias is by encouraging individuals to adopt reflective thinking (Croskerry, 2003; Evans, 2008). The significance of reflection in reducing bias is related to Kahneman's (2003, 2011) theory of dual processing, and reflective thinking is indeed a form of Type 2 thinking. Since bias is a consequence of Type 1 thinking, correcting the bias can be accomplished through analytical and reflective Type 2 thinking. Dewey (1933) defined reflective thinking as a type of thinking that considers alternative viewpoints and reasons prior to performing an action or adopting a belief. Reflection can lead students to consider the evidence rather than their feelings or emotions. Therefore, when students think analytically and critically in learning, especially when they are doing self-evaluation, they may be able to correct errors in their thinking and reduce overestimation of their performance (Zimmerman et al., 2011); hence, they can produce an accurate assessment (Hacker et al., 2000). Reflection can hinder students from being overconfident, as they conduct self-evaluation based on evidence. Lyons and Zelazo (2011) added that self-reflection allows students to adjust their cognition and behavior to improve accuracy and attain more excellent outcomes.

Finally, having good self-regulation is the final goal of cognitive debiasing. In the learning process, students do many cognitive activities. Winne and Jamieson-Noel (2002) warned that cognitive activities happen somewhat unconsciously, which leads students to make errors. Therefore, self-regulation is pivotal when students diagnose their own learning processes. Students with good self-regulation are able to counter cognitive pitfalls, therefore allowing them to be able to monitor and control their cognitive strategies (Heikkilä \& Lonka, 2006; Pintrich, 2000; Wolters, 1998). Even when the task demands change, self-regulated learners can modify the cognitive strategy into a more 
effective strategy and maintain their cognitive engagement (Pintrich \& De Groot, 1990; Zimmerman, 200o; Zimmerman \& Martinez-Pons, 1992). In other words, self-regulated learners understand how to learn and how to accomplish their academic goals by utilizing diverse cognitive strategies (Figure 1).

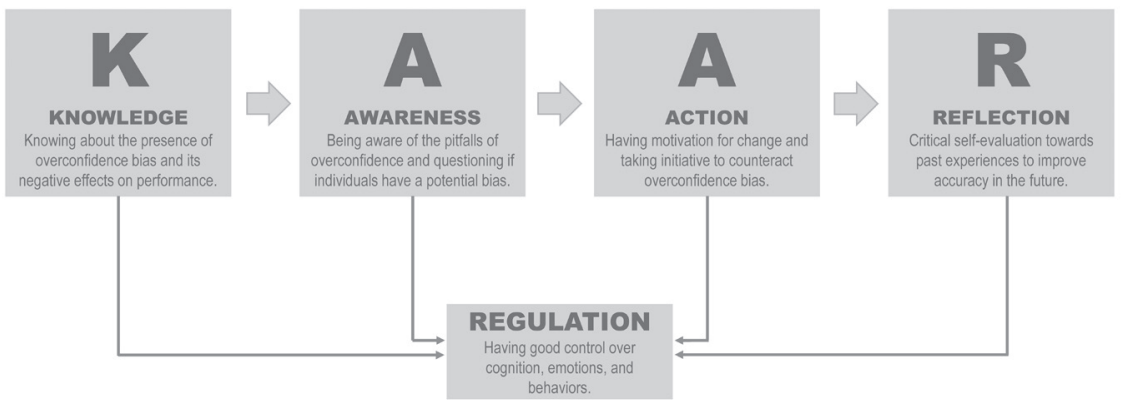

Sources: Knowledge: Aczel et al. (2015), Babcock and Loewenstein (1997). Fischhoff (1982): Awareness: Croskerry et al. (2013), Mair et al. (2014), Morewedge et al. (2015), Shepperd et al. Sources: Knowledge: Aczel et al. (2015), Babcock and Loewenstein (1997), Fischhoff (1982); Awareness: Croskerny et al. (2013), Mair et al. (2014), Morewedge et al. (2015), Shepperd et al.
(2018); Action: Croskerry et al. (2013), Kahneman et al. (2011); Reflection: Croskerry (2003), Evans (2008), Hacker et al. (2000), Lyons and Zelazo (2011), Zimmerman et al. (2011); Regulation: Heikkilä and Lonka (2006). Pintrich (2000). Zimmerman (2000).

FIGURE 1 KAAR model to debias the overconfidence.

Based on the KAAR model, we designed intervention activities to support the efficacy of each stage of KAAR to debias overconfidence among students in the classroom. The description of intervention activities is presented in Section 4.

\section{$3 \quad$ Research Questions}

In this study, we examined whether the intervention activities of the KAAR model could help students to reduce overconfidence bias. Furthermore, as students might be influenced by intervention to different degrees, we ran a trajectory analysis to characterize the pattern of overconfidence bias, providing specific information to understand how students' overconfidence changed during the intervention. Accordingly, we had the following research questions as the focus of this study:

1. To what extent can the KAAR intervention activities reduce the overconfidence bias of undergraduate students in the biology classroom?

2. What patterns of change in students' levels of overconfidence can be found over the course of the intervention? 


\subsection{Participants}

Participants were 90 undergraduate students majoring biology education at an education-based university in Indonesia. We conducted this study in the compulsory human anatomy and physiology course in the third year of the biology education major. The course content was about principles of anatomy and physiology of human body, including the organization and important chemical reactions of the human body, features and functions of the human body, and how these structures establish many complex systems. In this study, all participants were involved in the intervention.

\subsection{Overview of Intervention Activities}

The intervention activities of the KAAR model were developed from prior intervention studies for cognitive debiasing. At first, this was done to inform the students about overconfidence and build their awareness about their biases. Students watched a video about overconfidence, followed by a brief discussion with lecturers including samples of overconfidence bias from daily life. Morewedge et al.'s (2015) study used video had in debiasing intervention and succeeded in mitigating the participants' bias for at least two to three months.

Next, to encourage students to take the initiative in cognitive debiasing, the students' pre- and post-test answer sheets were given to them after the evaluation. Knowing their actual performance and the accuracy of their prediction (confidence level) on the correctness of their answer gives indirect feedback to the students. The role of the teacher after giving the evaluation is essential. Rather than perceiving the academic evaluation as a final point, it should be emphasized to students that evaluation should be viewed as valuable feedback and opportunity for further learning (Zimmerman et al., 2011). Accordingly, if the students discover they are overconfident, they might be motivated to start reducing their bias. However, some students have difficulty in recognizing their own biases, and therefore, a group discussion should be conducted as a collective action for debiasing. In the group discussion, one student's Type 2 thinking can help detect another students' overconfidence bias and correct it. In the present study, a group discussion helped students discuss their overconfidence, conduct peer assessment, and give feedback to each other about their levels of confidence. Feedback from others can reduce overconfidence amongst students (Ferretti et al., 2016; González-Vallejo \& Bonham, 2007).

Zimmerman et al. (2011) suggested that a key to reflection is self-evaluation after performance efforts. Writing a reflective statement and a study plan is a form of evaluation that supports students' reflection. Both encourage students 
to consider the challenges they encountered during the study and how they will overcome these challenges in the future (Tsingos-Lucas et al., 2016). In writing reflective statements, students were guided by questions such as "What is the most important thing you have learned in this chapter?" "Which concepts in this chapter have you mastered, and which concepts have you not mastered? Why?" "Before the test, what score did you expect to get on the test?" and "When you compare the estimated and the actual scores you got on the test, what do you think about your confidence level?" Through reflective statements, students respond to their performance outcomes and their ability to control their confidence level, which influences them to make adaptive selfreactions. Additionally, the study plan guides students on how to evaluate the prior strategies they used for learning. Students are asked questions such as, "What strategy did you use to learn the concepts in this chapter?" "After studying, what did you do to ensure that you understood concepts in this chapter?" "Do you think your learning strategy has been effective enough for you to master the concepts in this chapter? Why and why not?" and "If you found your strategy is not effective, did you plan a new learning strategy? If yes, what was your strategy for studying concepts in the following chapter? If no, why?" The study plan allows students to modify their learning strategies for the next lesson. Foster et al. (2017) have argued that students learn a subject efficiently when they understand what they need to prioritize in learning.

To summarize, Table 1 is an overview of the intervention activities of the KAAR model for reducing overconfidence.

\section{Stage of Debiasing Activities Description}

$\begin{array}{lll}\begin{array}{l}\text { Knowledge } \\ \text { Awareness }\end{array} & \begin{array}{l}\text { Video about } \\ \text { overconfidence }\end{array} & \begin{array}{l}\text { The video contains information about (a) what } \\ \text { overconfidence bias is, (b) why people are } \\ \text { overconfident, (c) how overconfidence is related } \\ \text { to the Dunning-Kruger effect, (d) what the } \\ \text { negative impact of overconfidence is, and } \\ (\mathrm{e}) \text { how you can overcome overconfidence. } \\ \text { The video is followed by a brief discussion with } \\ \text { teachers about overconfidence. }\end{array} \\ & \begin{array}{l}\text { This test is used to measure students' } \\ \text { overconfidence bias. In addition, it helps the } \\ \text { Tction }\end{array} & \begin{array}{l}\text { students to be more cautious when they take } \\ \text { scale (pre- and } \\ \text { post-test) }\end{array} \\ & \begin{array}{l}\text { a test. The test result will be given as students } \\ \text { indirect feedback for their calibration. }\end{array}\end{array}$




\section{Stage of Debiasing Activities Description}

Group discussion Based on the worksheet, the students work in a group and discuss overconfidence. They then perform a peer-assessment activity by providing each other feedback about their confidence level.

\begin{tabular}{|c|c|c|}
\hline Reflection & Reflective statement & $\begin{array}{l}\text { The students are given open-ended questions to } \\
\text { guide the reflection process after finishing the } \\
\text { chapter and receiving the post-test result. The } \\
\text { reflection includes questions about how well } \\
\text { the students understood the concept along with } \\
\text { details on their confidence level while they were } \\
\text { taking the test compared to the actual test result. } \\
\text { Similar to the reflective statement, the students } \\
\text { are also given open-ended questions to reflect on } \\
\text { the effectiveness of their prior learning strategy } \\
\text { and plan a future approach if necessary. }\end{array}$ \\
\hline
\end{tabular}

\subsection{Design and Procedure}

The study was a one-group pre- and post-test quasi-experimental design to evaluate whether the intervention activities of KAAR model could reduce overconfidence among students during biology class. The intervention consisted of 16 meetings, each with a length of 75 minutes, spread out over a period of three months for a total of 20 hours. The meetings were divided into sections based on the three main chapters of the course: the digestive system (6 meetings), the reproductive system (4 meetings), and the urinary system (6 meetings). Given the total time of intervention, this study had a short intervention that did not interrupt the process of education. Figure 2 presents the details of the intervention timeline.

\subsection{Instrument}

The instrument used to assess overconfidence evaluated the monitoring judgment of test performance. There are two types of monitoring judgments: those at the test level (global method) and on every single test item (local method; Händel, de Bruin, \& Dresel, 2020; Nietfeld et al., 2005; Schraw, 2009). At the global level, students usually indicate the number of items they thought they had answered correctly or indicate their confidence level in their performance 


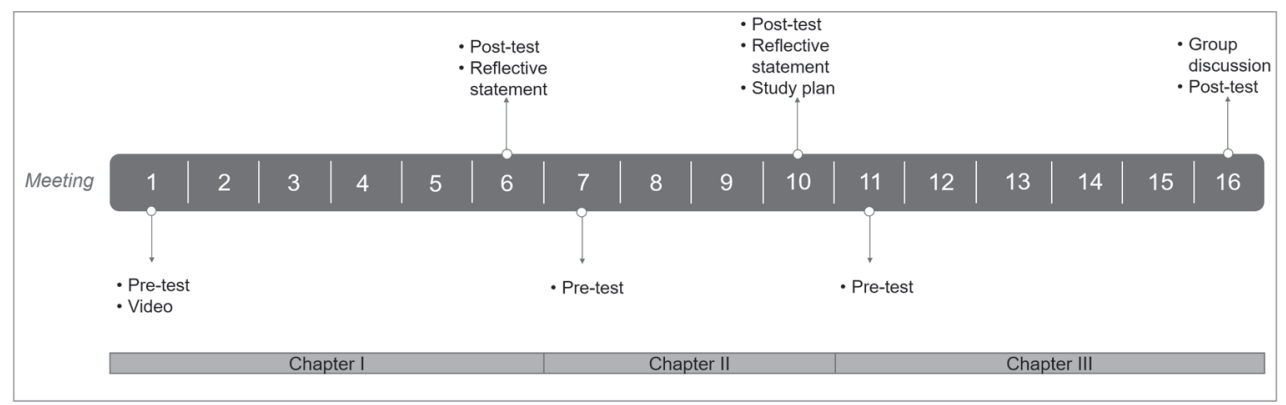

FIGURE 2 The timeline of intervention.

on the test taken. Meanwhile, in the local method, after each test item, students were asked to give judgment on how confident they were about the correctness of their answers (Nietfeld et al., 2005). As the local judgment gains specific and rich information on students' confidence levels for each item, this study assessed students' overconfidence using dichotomous assessment using the local method (Händel et al., 202O).

In the present study, overconfidence was assessed using a two-tier instrument consisting of multiple-choice questions (concept test) and a confidence scale. Multiple-choice items with five options were selected from the book of examination questions and answers in basic anatomy and physiology (Caon, 2018) by considering heterogeneity and question difficulty. The confidence level that was added to each item was a five-point Likert scale $(1=$ strongly not confident and 5 = strongly confident) to indicate the students' confidence in the correctness of their answers to questions. A representative sample of the items is shown in Table 2.

TABLE 2 The sample items used to assess the students' overconfidence

Chapter Multiple choice Confidence scale

Reproductive system
8. Which of the following statements is correct?

A. Ova all contain a Y chromosome.

B. Half of the ova carry an $\mathrm{X}$ chromosome and half carry a Y chromosome.

C. Half of the sperm cells carry an $\mathrm{X}$ chromosome and half carry a Y chromosome.
8-1 How confident are you with your answer to the above question?

(1) Strongly not confident

(2) Not confident

(3) Fairly confident

(4) Confident

(5) Strongly confident 
TABLE 2 The sample items used to assess the students' overconfidence (cont.)

\begin{tabular}{ll} 
Chapter & Multiple choice \\
\hline D. Sperm all carry an X chromosome. \\
E. None is right
\end{tabular}

Urinary

system
Confidence scale
E. None is right

5. When systemic blood pressure increases, how does the kidney respond to maintain glomerular filtration rate?
A. The afferent arteriole dilates.
B. The afferent arteriole constricts.
C. The efferent arteriole dilates.
D. The efferent arteriole constricts.
E. Both afferent and efferent dilate.

5-1 How confident are you with your answer to the above question?

(1) Strongly not confident

(2) Not confident

(3) Fairly confident

(4) Confident

(5) Strongly confident

SOURCE: EXAMINATION QUESTIONS AND ANSWERS IN BASIC ANATOMY AND PHYSIOLOGY (CAON, 2018)

The concept test was scored using a 1 for correct answers and a $o$ for incorrect answers on each item. Meanwhile, the scoring for overconfidence bias employed the local method to detect overconfidence bias by comparing the concept test score and confidence level of each individual item. For instance, if students gave an incorrect answer (o) for an item in the concept test and their confidence level in that item was 3 (fairly confident) to 5 (strongly confident), the overconfidence bias for that item will be scored 1 . If the students gave an incorrect answer (o) for an item in the concept test and their confidence level in that item was 1 (strongly not confident) or 2 (not confident), the overconfidence bias for that item was scored o. Likewise, when students gave a correct answer (1) for an item in the concept test and chose any point ( 1 to 5 ) on the confidence scale, their overconfidence bias for that item was scored o.

\subsection{Data Analysis}

For each exam, we calculated the mean concept score (knowledge), the mean confidence level, and the mean overconfidence bias. To analyze these data, two analyses were performed. First, a paired sample $t$-test using I BM sPSs Statistics 24 to compare the mean difference between pre-test and post-test for concept score (knowledge), confidence level, and overconfidence score. Cohen's $d$ was also analyzed to calculate the effect size of a significant difference. 
Second, we conducted a trajectory analysis by performing group-based trajectory modeling (GBTM). Trajectory analysis was performed to evaluate which students the intervention had an impact on. Previous studies have commonly used the general pattern of the data to evaluate whether students were affected by the intervention. However, students may be influenced by the intervention to different degrees. Trajectory analysis is beneficial for documenting students' heterogeneous responses to the intervention so that we can understand the students' overconfidence patterns precisely. GBTM classifies students into subgroups based on changes in their overconfidence at each time point and reveals how these subgroups perform throughout the intervention (Lee et al., 2015).

Using longitudinal data of overconfidence mean scores during the intervention, G BTM was performed using crimCV, a package in R software that can predict the number of groups in longitudinal data using the cross-validation error method (CVE). This method was developed by Nielsen et al. (2014) to address the limitations of the Bayesian information criterion (BIC) and the Akaike information criterion (AIC) values in examining the number of latent groups for longitudinal data. BIC and AIC values often fail to compute the accurate maximum likelihood estimation (MLE). Thus, the CVE method was used to compute MLE in a more accurate way. Nielsen et al. (2014) recommended that the model with the lowest CVE index is the best one to fit with the data. Therefore, we chose the GBTM model, which had the lowest CVE index. However, since AIC and BIC value are widely used to decide the fitness of a model, we also considered both values in deciding the model with the best fit for this study.

\section{$5 \quad$ Results}

\subsection{Comparison of Knowledge and Overconfidence Bias during the Intervention}

Table 3 lists descriptive statistics from the result of paired $t$-test analysis together with the effect size. According to Cohen (1992), the effect size is interpreted as negligible for $d=0$ to $d=0.19$, small for $d=0.20$ to $d=0.49$, medium for $d=0.50$ to $d=0.79$, and large $d=0.80$ and above.

As shown in Table 3 , students' knowledge for all chapters increased significantly $(p<.001)$ from pre-test to post-test. Effect sizes for the first chapter and the second chapter were large, while for the third chapter it was small. Similarly, students' confidence levels increased significantly $(p<.001)$ in all post-tests. On the other hand, the overconfidence score was only significant in Chapters 1 and 3. In the first chapter $\left(M_{\text {pret }}=0.451, M_{\text {post }}=0.331\right)$, the score decreased 
TABLE 3 The comparison of mean values of knowledge, confidence level, and overconfidence

\begin{tabular}{|c|c|c|c|c|c|c|c|}
\hline & & \multicolumn{2}{|c|}{ Chapter 1} & \multicolumn{2}{|c|}{ Chapter 2} & \multicolumn{2}{|c|}{ Chapter 3} \\
\hline & & Pre & Post & Pre & Post & Pre & Post \\
\hline \multirow[t]{5}{*}{ Knowledge } & Mean & 0.259 & 0.529 & $0.45^{\circ}$ & $0.6 \circ 3$ & 0.277 & 0.347 \\
\hline & SD & 0.130 & 0.194 & 0.148 & 0.144 & 0.122 & 0.126 \\
\hline & $t$-value & \multicolumn{2}{|c|}{-10.92} & \multicolumn{2}{|c|}{-7.48} & \multicolumn{2}{|c|}{-4.19} \\
\hline & $p$-value & \multicolumn{2}{|c|}{.000} & \multicolumn{2}{|c|}{.000} & \multicolumn{2}{|c|}{.000} \\
\hline & Cohen's $d$ & \multicolumn{2}{|c|}{-1.18} & \multicolumn{2}{|c|}{-0.84} & \multicolumn{2}{|c|}{-0.47} \\
\hline \multirow[t]{5}{*}{ Confidence } & Mean & 2.766 & 3.081 & 2.699 & $3 \cdot 335$ & 2.307 & 2.662 \\
\hline & SD & 0.527 & 0.490 & 0.540 & 0.597 & 0.569 & 0.578 \\
\hline & $t$-value & \multicolumn{2}{|c|}{-4.43} & \multicolumn{2}{|c|}{-9.18} & \multicolumn{2}{|c|}{-5.94} \\
\hline & $p$-value & \multicolumn{2}{|c|}{.000} & \multicolumn{2}{|c|}{.000} & \multicolumn{2}{|c|}{.000} \\
\hline & Cohen's $d$ & \multicolumn{2}{|c|}{-0.48} & \multicolumn{2}{|c|}{-1.03} & \multicolumn{2}{|c|}{-0.67} \\
\hline \multirow[t]{5}{*}{ Overconfidence } & Mean & $0.45^{1}$ & 0.331 & 0.279 & 0.298 & 0.272 & 0.340 \\
\hline & SD & 0.215 & 0.222 & 0.165 & 0.163 & 0.222 & 0.207 \\
\hline & $t$-value & \multicolumn{2}{|c|}{4.16} & \multicolumn{2}{|c|}{-0.97} & \multicolumn{2}{|c|}{-2.91} \\
\hline & $p$-value & \multicolumn{2}{|c|}{.000} & \multicolumn{2}{|c|}{.330} & \multicolumn{2}{|c|}{.005} \\
\hline & Cohen's $d$ & \multicolumn{2}{|c|}{0.45} & \multicolumn{2}{|c|}{-0.11} & \multicolumn{2}{|c|}{-0.32} \\
\hline
\end{tabular}

significantly $(p<.001)$, although the effect size was relatively small $(d=0.45)$. However, students' overconfidence score in the third chapter $\left(M_{\text {pre }}=0.272\right.$, $\left.M_{\text {post }_{3}}=0.340\right)$ increased significantly with a small effect size $(p<.05, d=0.32)$.

5.2 The Pattern of Students' Overconfidence Bias during the Intervention To address the second research question, we analyzed whether the students' overconfidence bias during the intervention analyzed by trajectory analysis had a single or distinct patterns. Based on analysis results, a five-group trajectory model was suggested as the best model for examining changes of overconfidence score $(\mathrm{CVE}=13.16$; $\mathrm{BIC}=6081.22 ; \mathrm{AIC}=5999.68)$.

Figure 3 shows the plot of mean overconfidence scores of five groups of students over six tests during the intervention. The percentage of students in each trajectory group is also presented. As an overall result, the five groups of students had a similar pattern between Pre 1 and Post 1 in that the overconfidence 


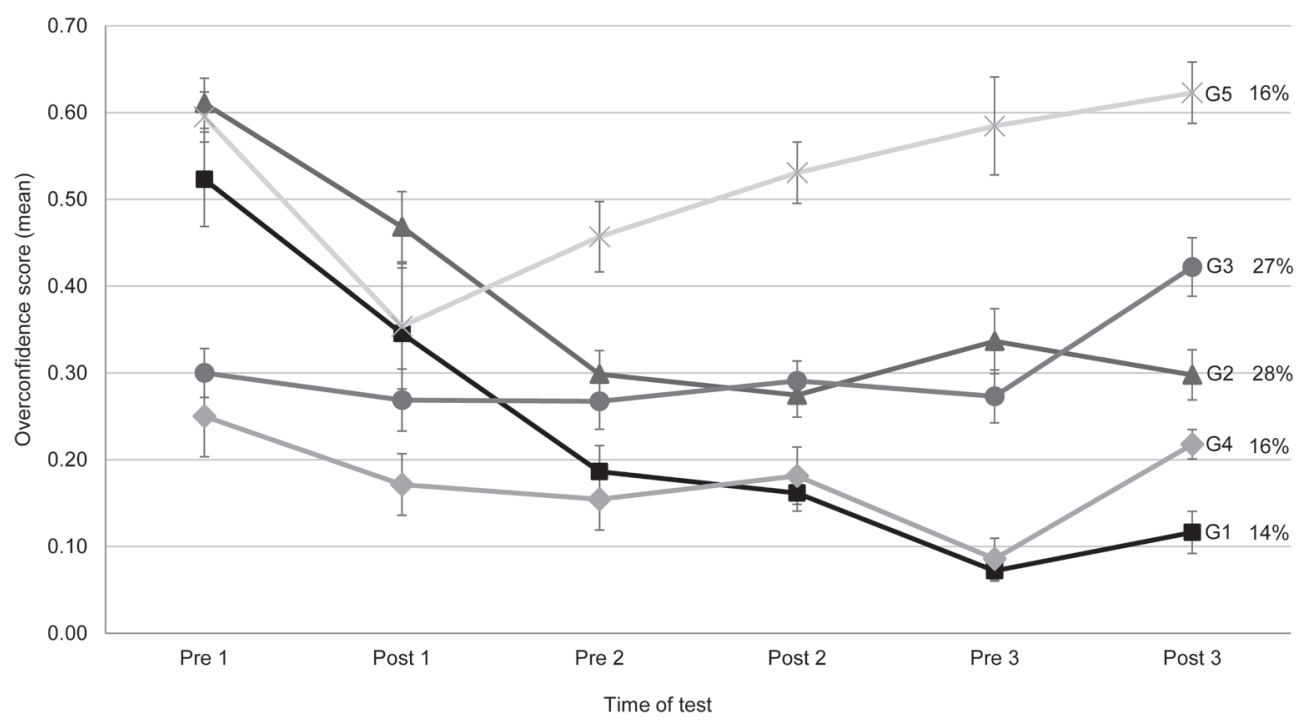

FIGURE 3 Students' overconfidence groups based on the trajectory patterns. G1: The most effective group; G2: The second most effective group; G3: The "little learning effect" group; G4: The least effective group; $\mathrm{G}_{5}$ : The upward trend group.

among the whole group decreased. However, the overconfidence pattern after Post 1 was diverse. Some groups remained constant, while others showed a decreasing or an increasing pattern.

Of the five groups, the groups of students that were most likely to be affected by the intervention were G1 (14\%), followed by G2 (28\%). The number of students in these two groups was relatively high $(42 \%)$. G4 (16\%) was the group of students affected the least by the intervention. Their overconfidence tended to be capricious from the beginning to the end of the intervention. G3's $(27 \%)$ overconfidence score remained constant along the intervention, although it suddenly increased in the last test. G5's (16\%) overconfidence only decreased from the first test to the second test and consistently increased from the following test until the last test. Interestingly, although the groups showed different overconfidence patterns, students' performance (concept test) was similar across the six tests (pre-test and post-test), as shown in Figure 4.

The knowledge within groups was not highly different across the six tests, although confidence levels were diverse among the five trajectory groups. The $\mathrm{G}_{5}$ trajectory group's knowledge in particular tend to be lower than other groups', while their confidence level tended to be higher, consistent with results shown in Figure 3 that presented an upward trend within $\mathrm{G}_{5}$ group students. 

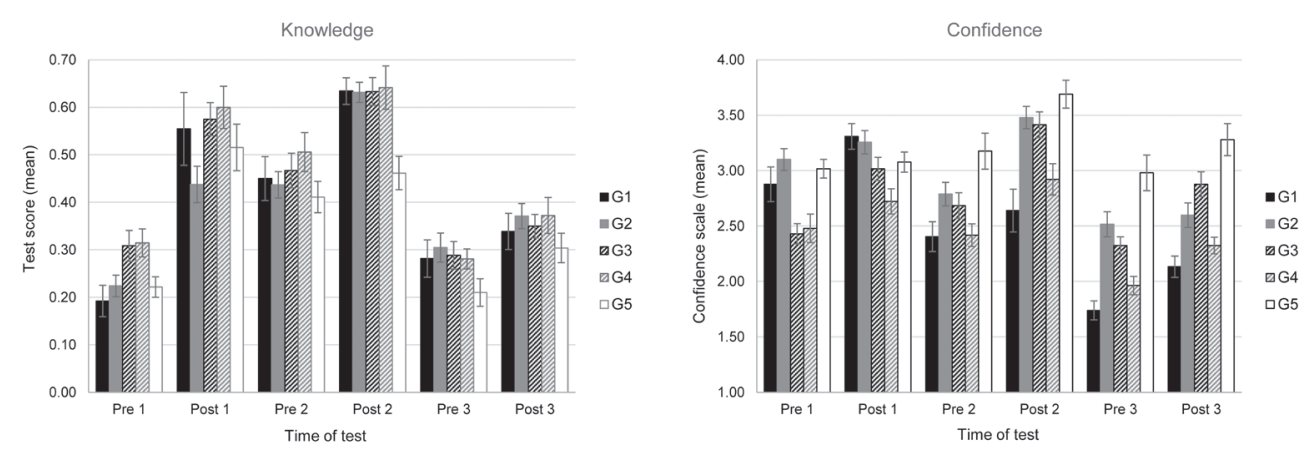

FIGURE 4 Student's knowledge and confidence levels during intervention.

\section{Discussion}

The findings of the present study may contribute to the literature on intervention for reducing overconfidence bias in the classroom setting, especially in biology teaching and learning. This research was aimed at determining to what extent the intervention activities of the KAAR model could debias overconfidence among biology education majors. In addition, the study analyzed the pattern of the change of students' overconfidence bias during intervention. The following two research questions guided the discussion.

First, to what extent do the KAAR intervention activities reduce the overconfidence bias of undergraduate students? The results showed that watching a video about overconfidence is likely the most significant activity that can reduce students' overconfidence. This is shown by the significant decrease in the first chapter of the intervention, where the video was delivered in the interval between Pre 1 and Post 1 . In this study, the video introduced the topic of overconfidence bias to students, along with why and how this occurs, why it has detrimental consequences, and so forth. By knowing about overconfidence bias and its negative impacts, students were able to change their perceptions of their own confidence. Therefore, they understood that if this confidence becomes overconfidence rather than an advantage, it will lead them to disruptive behavior and even to poor academic performance. This video also warned the students that overconfidence bias could unconsciously occur to everyone, regardless of their social and intellectual domains, particularly when having an excessively confident belief about something. According to Morewedge et al. (2015), video is an efficient tool to teach such cognitive skills, including attempts to reduce cognitive biases. This is related to the effectiveness of videos in promoting the watchers' acceptance of the information being 
demonstrated (Downs, 2014). In addition, Dahlstrom (2015) argued that videos make it easier for individuals to recall their memories, as they create episodic memories. Therefore, video not only constructs students' knowledge about overconfidence bias but also helps them to recall memories of similar situations. Following a brief discussion with lecturers after a video, students build their awareness that, as humans, they cannot escape from cognitive biases, including overconfidence. They can look back on past experiences of having too much confidence and later be more cautious when encountering situations related to self-confidence. Knowing about the presence of overconfidence bias and being aware of it leads students to be more careful and less overconfident in subsequent performance (Babcock \& Loewenstein, 1997; Mair et al., 2014).

On the other hand, having knowledge and awareness about overconfidence only had a transient effect on reducing bias. The increase in overconfidence among students from pre-test to post-test in the second and third chapter showed that educating people about bias only partially helps them to avoid it (Aczel et al., 2015; AlKhars et al., 2019). As awareness should be followed by action for maintaining the process of overconfidence debiasing, the activities encouraging students' actions in this study (i.e., indirect feedback from the test results and group discussion) did not work very well. This is because the action relies on students' personal motivations for change, which are quite difficult to influence. Rothman (2006) added that even though people clearly understand the drawbacks of their current behavior and know the benefit of changing it, lack of motivation is a formidable issue that stands in the way of performing an expected action. Accordingly, Croskerry et al. (2013) suggested that emotionladen experiences will help to motivate cognitive change.

Furthermore, activities facilitating students to become reflective thinkers, such as reflective statements and study plans, failed to show a significant impact on debiasing. This could be due to the failure of the action in the prior stage. The critical stage in sustaining the process of debiasing is taking steps where people apply strategic rules to override Type 1 thinking as the source of biases (Stanovich, 2011; Stanovich \& West, 2008). In the process of doing action to reduce overconfidence, people should be able to detect the need to inhibit being overconfident and sustain their action while they also discover alternative strategies (Stanovich \& West, 2008). Therefore, when a debiasing action is unsuccessful, none of the debiasing strategies will be applied, and, indeed, people will find it difficult to reflect.

Second, what patterns of change in students' levels of overconfidence can be found over the course of the intervention? Among the five groups (G1-G5), the most effective groups ( $\mathrm{G}_{1}$ and $\mathrm{G} 2$ ) successfully debiased their overconfidence for more than half of the time during the intervention period. Initially, 
they had a high level of overconfidence, but after participating in the intervention, they reduced their overconfidence in most of the test. This indicates that most of the debiasing activities along intervention worked to reduce their high level of overconfidence. However, the pattern of overconfidence of students who first had a low level of overconfidence $\left(\mathrm{G}_{3}\right.$ and $\left.\mathrm{G}_{4}\right)$ remained stable from the beginning. While $\mathrm{G}_{3}$ students' overconfidence score suddenly increased at the end of the intervention, $\mathrm{G}_{4}$ students' overconfidence score decreased at one point and then rose, reaching a point that was somewhat similar to that of the beginning. One possible way to explain the sudden increase in overconfidence among $\mathrm{G}_{3}$ students is that they surged to a "beginner's bubble" of overconfidence because of the little learning effect. This effect occurs in beginners who quickly believe they know a lot about something after small amounts of learning (Sanchez \& Dunning, 2018). G3 students took the first five tests quite cautiously. Nevertheless, after some learning and experience, they believed they had become more knowledgeable (Bengtsson, Persson, \& Willenhag, 2005; Destan \& Roebers, 2015). Such belief can lead students to overinflated self-perceptions of expertise while they are only novices.

Furthermore, $G_{5}$ students were greatly different from the other four groups of students. Even though $\mathrm{G}_{5}$ students had the initial high level of overconfidence similar to G2 students, G2 students succeeded in reducing their bias, while $G_{5}$ students showed an upward trend of overconfidence. At the end of the intervention, their overconfidence level even matched their initial point. We could not determine from data of this study an exact explanation for this phenomenon. Nonetheless, we inferred that $\mathrm{G}_{5}$ students were overconfident of their overconfidence. Because they had a clear understanding of overconfidence at the beginning of the intervention, the accuracy in Post 1 (based on indirect feedback from the test results) drove them to think that they could control their overconfidence. Therefore, in the following tests, instead of reducing their bias persistently, their overconfidence gradually escalated until the end of the intervention.

Overall, all groups shared some similarities. After the first intervention activity (the video), the pattern of overconfidence among the whole group showed a decline, indicating that introducing and building awareness about overconfidence bias can lead to removing it (Babcock \& Loewenstein, 1997; Mair et al., 2014). The diverse pattern of overconfidence after Post 1 revealed that knowing or being aware of overconfidence cannot maintain overconfidence debiasing (Aczel et al., 2015; AlKhars et al., 2019). Therefore, in the following stage, the action is considered the most decisive stage in determining whether or not students will continue to remove their overconfidence bias. If students have a motivation to change (action), they will continue the debiasing process, as G1 
and G2 students did. However, for students who were unsuccessful in the action phase, though some reflection activities were given, their overconfidence remained constant $\left(\mathrm{G}_{3}\right.$ and $\left.\mathrm{G}_{4}\right)$ and even increased $\left(\mathrm{G}_{5}\right)$.

Finally, it is noteworthy that student knowledge (concept test score) within the groups across the tests was identical. Meanwhile, the way students rated their confidence level showed diverse patterns, as depicted in Figure 4. With the same ability, some groups who judged their ability with a high confidence level tended towards overconfidence, while some groups were contradictory. Sanchez and Dunning (2018) explained there can be an imbalance in growth between knowledge and confidence levels. While knowledge rose smoothly, confidence grew tremendously.

\section{Conclusion}

The present study provided a new insight into debiasing overconfidence, one of the most ubiquitous cognitive biases in science instruction. By conducting some intervention activities using the KAAR model, students in our study showed five distinct patterns of overconfidence change throughout the intervention: the most and second most effective (reducing), the least effective and little learning effect (remained stable), and an upward trend. Among these activities, the most significant activity in reducing overconfidence was a video that successfully built students' knowledge and awareness about the bias, which was shown by the pattern of reduction of the five groups of students' overconfidence score between Pre 1 and Post 1, which was when the video was given. However, similar to prior studies, our findings suggest that getting knowledge and becoming aware of the bias could not maintain debiasing since some students remained or even increased their overconfidence through the course of the intervention after the introductory video. In the following step, the action or motivation to change was the most decisive stage that determined whether students would continue the debiasing process.

\section{$8 \quad$ Limitations and Future Research Recommendations}

Our study was conducted without employing a control group; therefore, the obvious limitation is that we could not rule out the possibility that reducing overconfidence bias in this study might be driven by another variable besides the intervention effect. Therefore, it is necessary to involve a control group in future intervention studies to reduce overconfidence bias. Additionally, 
because knowledge and awareness by themselves do little to rid students of overconfidence bias (Sellier, Scopelliti, \& Morewedge, 2019), more effective methods to support the action phase of debiasing are required. Action for debiasing happens if the motivation for change exists. However, cognitive biases are unconscious errors, and motivating ourselves to fix something that we cannot clearly see is a difficult thing; in other words, we need external parties to help us eliminate our biases. Therefore, Kahneman (2011) suggested that a group debiasing action would be tremendously beneficial for solving this issue. By correcting each other's biases, students positively affect groups' thinking and evaluation; therefore, systematic guidance for group debiasing processes has to be developed in future studies.

\section{Abbreviations}

$\begin{array}{ll}\text { AIC } & \text { Akaike Information Criterion } \\ \text { BIC } & \text { Bayesian Information Criterion } \\ \text { CVE } & \text { Cross Validation Error } \\ \text { GBTM } & \text { Group-based Trajectory Modeling } \\ \text { KAAR } & \text { Knowledge, Awareness, Action, Reflection }\end{array}$

\section{Acknowledgments}

We wish to express our gratitude to UPG RIs lecturers, Fibria Kaswinarni, S.Si., M.Si., and Ipah Budi Minarti, S.Pd., M.Pd., as well as their students for their contributions to and participation in this study. We also gratefully thank the anonymous reviewers for their helpful suggestions and feedback.

\section{Funding}

This study was funded by the National Research Foundation of Korea (NRF, NRF-2017RiC1B1005152) awarded to Minsu Ha.

\section{Ethical Considerations}

Ethical approval of the study was granted by the Kangwon National University Institutional Review Board, which the university with which one of the 
researchers is affiliated (Approval no. KWNUIRB-2017-O3-0O1-OO2). The board confirmed that the study did not violate human rights and that all content and processes conformed to the conduct of appropriate research ethics.

\section{About the Authors}

Ai Nurlaelasari Rusmana is a master's student in the Division of Science Education at Kangwon National University in Chuncheon, Republic of Korea. Before pursuing a masters' degree in Korea, she graduated from the biology education program at Universitas Pendidikan Indonesia. Her research focuses on cognitive biases, particularly overconfidence bias in science education. She is particularly interested in designing an intervention program for reducing the overconfidence bias for pre-service science teachers.

Fenny Roshayanti is a lecturer in the Department of Science Education, Postgraduate School at UPG RIS in Semarang, Indonesia. She holds a doctoral degree in science education from Universitas Pendidikan Indonesia in Bandung, Indonesia. Her research focuses on developing an assessment for argumentation skills among undergraduate biology students. She is also studying STEAM education in Indonesia. Currently, she is concerned with researching the use of STEAM education to improve life skills of elementary school students.

Minsu Ha is an associate professor in the Division of Science Education at Kangwon National University in Chuncheon, Republic of Korea. He holds a doctoral degree in science education from Ohio State University in the United States. His research focuses on identifying and reducing cognitive biases among students, particularly in science teaching and learning. He also researches the development of assessment tool-based artificial intelligence (AI) for openended assessment. He has been conducting joint research and project collaboration with Indonesian colleagues since 2014 .

\section{References}

Aczel, B., Bago, B., Szollosi, A., Foldes, A., \& Lukacs, B. (2015). Is it time for studying real-life debiasing? Evaluation of the effectiveness of an analogical intervention technique. Frontiers in Psychology, 6, 1120. https://doi.org/10.3389/fpsyg.2015.01120

AlKhars, M., Evangelopoulos, N., Pavur, R., \& Kulkarni, S. (2019). Cognitive biases resulting from the representativeness heuristic in operations management: an 
experimental investigation. Psychology Research and Behavior Management, 12, 263-276. https://doi.org/10.2147/PRBM.S193092

Babcock, L., \& Loewenstein, G. (1997). Explaining bargaining impasse: The role of self-serving biases. Journal of Economic Perspectives, 11(1), 109-126. https://doi .org/10.1257/jep.11.1.109

Bandura, A. (1997). Self-efficacy: The exercise of control. New York, USA: W. H. Freeman.

Bengtsson, C., Persson, M., \& Willenhag, P. (2005). Gender and overconfidence. Economics Letters, 86(2), 199-203. https://doi:10.1016/j.econlet.2004.07.012

Bol, L., \& Hacker, D. J. (2001). A comparison of the effects of practice tests and traditional review on performance and calibration. The Journal of Experimental Education, 69(2), 133-151. https://doi.org/10.108o/oo22097010960o653

Burton, R. A. (2008). On being certain: Believing you are right even when you're not. New York, USA: St. Martin's Press.

Camerer, C. F., \& Hogarth, R. M. (1999). The effects of financial incentives in experiments: A review and capital-labor-production framework. Journal of Risk and Uncertainty, 19(1-3), 7-42. https://doi.org/10.1023/A:1007850605129

Caon, M. (2018). Examination questions and answers in basic anatomy and physiology. Cham, Switzerland: Springer International Publishing AG.

Caplin, A., \& Leahy, J. V. (2019). Wishful Thinking. NB ER Working Papers 25707, National Bureau of Economic Research, Inc.

Cohen, J. (1992). A power primer. Psychological Bulletin, 112(1), 155. https://doi.org/ 10.1037//o033-2909.112.1.155

Croskerry, P. (2003). The importance of cognitive errors in diagnosis and strategies to minimize them. Academic Medicine, 78(8), 775-780. https://doi.org/10.1097/ ooo01888-200308000-00003

Croskerry, P., Singhal, G., \& Mamede, S. (2013). Cognitive debiasing 2: impediments to and strategies for change. BMJ Qual Saf, 22(Suppl 2), ii65-ii72. https://doi.org/ 10.1136/bmjqs-2012-0o1713

Dahlstrom, M. F. (2015). The moderating influence of narrative causality as an untapped pool of variance for narrative persuasion. Communication Research, 42(6), 779-795. https://doi.org/10.1177/oo93650213487374

Destan, N., \& Roebers, C. M. (2015). What are the metacognitive costs of young children's overconfidence?. Metacognition and Learning, 10(3), 347-374. https:// doi.org/10.1007/s11409-014-9133-Z

Dewey, J. (1933). How We Think: A Restatement of the Relation of Reflective Thinking to the Educative Process. Boston, USA: D.C. Heath \& Co Publishers.

Downs, J. S. (2014). Prescriptive scientific narratives for communicating usable science. Proceedings of the National Academy of Sciences, 111(4), 13627-13633. https:// doi.org/10.1073/pnas.1317502111 
Dunlosky, J., \& Rawson, K. A. (2012). Overconfidence produces underachievement: Inaccurate self evaluations undermine students' learning and retention. Learning and Instruction, 22(4), 271-28o. https://doi.org/10.1016/j.learninstruc.2011.08.003

Dunning, D. (2011). The Dunning-Kruger effect: On being ignorant of one's own ignorance. In J. Olson and M. P. Zanna (Eds.), Advances in experimental social psychology (pp. 247-296). New York: Elsevier.

Dunning, D., Johnson, K., Ehrlinger, J., \& Kruger, J. (2003). Why people fail to recognize their own incompetence. Current Directions in Psychological Science, 12(3), 83-87. https://doi.org/10.1111/1467-8721.01235

Erat, S., Haluk, C. S., \& Demirkol, K. (2016). Overconfidence in Classroom. Cadmo, 5769. https://doi.org/10.328o/CAD2016-001007

Evans, J. S. B. (2008). Dual-processing accounts of reasoning, judgment, and social cognition. Annual Review of Psychology, 59, 255-278. https://doi.org/10.1146/annurev .psych.59.103006.093629

Ferretti, V., Guney, S., Montibeller, G., \& von Winterfeldt, D. (2016). Testing best practices to reduce the overconfidence bias in multi-criteria decision analysis. In 2016 49th Hawaii International Conference on System Sciences (HICSS), USA, 16, 1547-1555.

Fischhoff, B. (1982). Debiasing. In D. Kahneman, P. Slovic, and A. Tversky (Eds.), Judgment under uncertainty: Heuristics and biases (pp. 422-444). Cambridge: Cambridge University Press.

Foster, N. L., Was, C. A., Dunlosky, J., \& Isaacson, R. M. (2017). Even after thirteen class exams, students are still overconfident: the role of memory for past exam performance in student predictions. Metacognition and Learning, 12(1), 1-19. https://doi .org/10.1007/s11409-016-9158-6

Gasparatou, R. (2017). Philosophy for/with children (P4C) \& the development of epistemically virtuous agents. In M. Gregory, J. Haynes, \& K. Murris (Eds.), The Routledge international handbook of philosophy for children (pp. 103-111). London: Routledge.

González-Vallejo, C., \& Bonham, A. (2007). Aligning confidence with accuracy: Revisiting the role of feedback. Acta Psychologica, 125(2), 221-239. https://doi.org/ 10.1016/j.actpsy.2006.07.010

Hacker, D. J., Bol, L., \& Bahbahani, K. (2008). Explaining calibration accuracy in classroom contexts: The effects of incentives, reflection, and explanatory style. Metacognition and Learning, 3(2), 101-121. https://doi.org/10.1007/s11409-008-9021-5

Hacker, D. J., Bol, L., Horgan, D. D., \& Rakow, E. A. (2000). Test prediction and performance in a classroom context. Journal of Educational Psychology, 92(1), 16o-170. https://doi.org/10.1037/0o22-0663.92.1.16o

Händel, M., de Bruin, A. B., \& Dresel, M. (2020). Individual differences in local and global metacognitive judgments. Metacognition and Learning, 15, 51-75. https://doi .org/10.1007/s11409-020-0922O-O 
Heikkilä, A., \& Lonka, K. (2006). Studying in higher education: students' approaches to learning, self-regulation, and cognitive strategies. Studies in Higher Education, 31(1), 99-117. https://doi.org/10.1080/o3075070500392433

Kahneman, D. (2003). A perspective on judgment and choice: mapping bounded rationality. American psychologist, 58(9), 697-720. https://doi.org/10.1037/ ooo3-o66X.58.9.697

Kahneman, D. (2011). Thinking, fast and slow. New York, NY: Macmillan.

Kahneman, D., Lovallo, D., \& Sibony, O. (2011). Before you make that big decision. Harvard Business Review, 89(6), 50-6o.

Kitsantas, A., Ware, H. W., \& Cheema, J. (2010). Predicting mathematics achievement from mathematics efficacy: Does analytical method make a difference? The International Journal of Educational and Psychological Assessment, 5(1), 25-44.

Kruger, J., \& Dunning, D. (1999). Unskilled and unaware of it: how difficulties in recognizing one's own incompetence lead to inflated self-assessments. Journal of Personality and Social Psychology, 77(6), 1121-1134. https://doi.org/10.1037/oo22-3514.77.6.1121

Labuhn, A. S., Zimmerman, B. J., \& Hasselhorn, M. (2010). Enhancing students' self-regulation and mathematics performance: The influence of feedback and self-evaluative standards. Metacognition and learning, 5(2), 173-194. https://doi .org/10.1007/s11409-010-9056-2

Lee, U. J., Sbeglia, G. C., Ha, M., Finch, S. J., \& Nehm, R. H. (2015). Clicker score trajectories and concept inventory scores as predictors for early warning systems for large STEM classes. Journal of Science Education and Technology, 24(6), 848-86o.

Lyons, K. E., \& Zelazo, P. D. (2011). Monitoring, metacognition, and executive function: Elucidating the role of self-reflection in the development of self-regulation. In J. B. Benson (Ed.), Advances in child development and behavior (pp. 379-412). London, UK: Elsevier.

Mair, C., Shepperd, M., \& Jorgensen, M. (2014). Debiasing through raising awareness reduces the anchoring bias. Poster presented at 2014 British Psychological Society Annual Conference, Birmingham, UK.

Mathabathe, K. (2019). Factors underlying metacognitive judgments in foundation chemistry. EURASIA Journal of Mathematics, Science and Technology Education, 15(5), em1712. https://doi.org/10.29333/ejmste/105868

Miller, T. M., \& Geraci, L. (2011). Unskilled but aware: Reinterpreting overconfidence in low-performing students. Journal of Experimental Psychology: Learning, Memory, and Cognition, 37(2), 502-506. https://doi.org/10.1037/aoo21802

Morewedge, C. K., Yoon, H., Scopelliti, I., Symborski, C. W., Korris, J. H., \& Kassam, K. S. (2015). Debiasing decisions: Improved decision making with a single training intervention. Policy Insights from the Behavioral and Brain Sciences, 2(1), 129-140. https:// doi.org/10.1177/2372732215600886

Myers, D. G. (1998). Social psychology (5th ed.). New York, USA: McGraw-Hill. 
Neuman, R., Rafferty, A., \& Griffiths, T. (2014). A bounded rationality account of wishful thinking. In P. Bello, M. Guarini, M. McShane, \& B. Scassellati (Eds.), Proceedings of the 36th Annual Meeting of the Cognitive Science Society (pp. 1210-1215). Austin, TX: Cognitive Science Society.

Nielsen, J. D., Rosenthal, J. S., Sun, Y., Day, D. M., Bevc, I., \& Duchesne, T. (2014). Group-based criminal trajectory analysis using cross-validation criteria. Communications in Statistics-Theory and Methods, 43(20), 4337-4356. https://doi.org/10 .1080/03610926.2012.719986

Nietfeld, J. L., Cao, L., \& Osborne, J. W. (2005). Metacognitive monitoring accuracy and student performance in the postsecondary classroom. The Journal of Experimental Educational, 74(1), 7-28. https://doi.org/10.2307/20157410

Nietfeld, J. L., Cao, L., \& Osborne, J. W. (2006). The effect of distributed monitoring exercises and feedback on performance, monitoring accuracy, and self-efficacy. Metacognition andLearning, 1(2),159-179.https://doi.org/10.1007/s10409-0o6-9595-6

Pintrich, P. R. (2000). Issues in self-regulation theory and research. The Journal of Mind and Behavior, 21(1/2), 213-219.

Pintrich, P. R., \& De Groot, E. V. (1990). Motivational and self-regulated learning components of classroom academic performance. Journal of Educational Psychology, 82(1), 33-40. https://doi.org/10.1037/0022-0663.82.1.33

Rachmatullah, A., \& Ha, M. (2019). Examining high-school students' overconfidence bias in biology exam: a focus on the effects of country and gender. International Journal of Science Education, 41(5), 652-673. https://doi.org/10.1080/09500693.2019.1578002

Rothman, A. J. (2006). Initiatives to motivate change: A review of theory and practice and their implications for older adults. In L. L. Carstensen, C. R. Hartel (Eds.), National Research Council (US) committee on aging frontiers in social psychology, personality, and adult developmental psychology. Washington, USA: National Academies Press.

Sanchez, C., \& Dunning, D. (2018). Overconfidence among beginners: Is a little learning a dangerous thing?. Journal of Personality and Social Psychology, 114(1), 10-28. https://doi.org/10.1037/pspaoooo102

Schraw, G. (2009). A conceptual analysis of five measures of metacognitive monitoring. Metacognition and learning, 4(1), 33-45. https://doi.org/10.1007/s11409-0o8-9031-3

Schraw, G., Wise, S. L., \& Roos, L. L. (2000). Metacognition and computer-based testing. In G. Schraw \& J. C. Impara (Eds.), Issues in the measurement of metacognition (pp. 223-26o). Lincoln, NE: Buros Institute of Mental Measurement.

Scopelliti, I., Morewedge, C. K., McCormick, E., Min, H. L., Lebrecht, S., \& Kassam, K. S. (2015). Bias blind spot: Structure, measurement, and consequences. Management Science, 6r(10), 2468-2486. https://doi.org/10.1287/mnsc.2014.2096

Sellier, A. L., Scopelliti, I., \& Morewedge, C. K. (2019). Debiasing training improves decision making in the field. Psychological Science, 30(9), 1371-1379. https://doi .org/10.1177/0956797619861429 
Serra, M. J., \& DeMarree, K. G. (2016). Unskilled and unaware in the classroom: College students' desired grades predict their biased grade predictions. Memory \& cognition, 44(7), 1127-1137. https://doi.org/10.3758/s13421-016-o624-9

Sheldrake, R. (2016). Differential predictors of under-confidence and over-confidence for mathematics and science students in England. Learning and Individual Differences, 49, 305-313. https://doi.org/10.1016/j.lindif.2016.05.0o9

Shepperd, M., Mair, C., \& Jørgensen, M. (2018). An experimental evaluation of a debiasing intervention for professional software developers. Proceedings of the $33 \mathrm{rd}$ Annual ACM Symposium on Applied Computing, France, 1510-1517.

Stankov, L., \& Lee, J. (2014). Overconfidence across world regions. Journal of Cross-Cultural Psychology, 45(5), 821-837. https://doi.org/10.1177/0022022114527345

Stanovich, K. (2011). Rationality and the reflective mind. New York, USA: Oxford University Press.

Stanovich, K. E., \& West, R. F. (2008). On the relative independence of thinking biases and cognitive ability. Journal of Personality and Social Psychology, 94(4), 672-695. https://doi.org/10.1037/0o22-3514.94.4.672

Tsingos-Lucas, C., Bosnic-Anticevich, S., Schneider, C. R., \& Smith, L. (2016). The effect of reflective activities on reflective thinking ability in an undergraduate pharmacy curriculum. American Journal of Pharmaceutical Education, 8o(4), 65. https://doi .org/10.5688/ajpe80465

van Geene, K., de Groot, E., Erkelens, C., \& Zwart, D. (2016). Raising awareness of cognitive biases during diagnostic reasoning. Perspectives on Medical Education, 5(3), 182-185. https://doi.org/10.1007/s40037-016-0274-4

Visé, M., \& Schneider, W. (2000). Determinants of performance prediction in kindergarten and school children: The importance of metacognitive and motivational factors. [Determinanten der Leistungsvorhersage bei Kindergarten- und Grundschulkindern: Zur Bedeutung metakognitiver und motivationaler Einflußfaktoren]. Zeitschrift fuer Entwicklungspsychologie und Paedagogische Psychologie, $32,5^{1-58}$.

White, B. Y., \& Frederiksen, J. R. (1998). Inquiry, modeling, and metacognition: Making science accessible to all students. Cognition and Instruction, 16(1), 3-118. https://doi .org/10.1207/s153269oxci16o1_2

Winne, P. H., \& Jamieson-Noel, D. (2002). Exploring students' calibration of self reports about study tactics and achievement. Contemporary Educational Psychology, 27(4), 551-572. https://doi.org/10.1016/So361-476X(o2)oooo6-1

Wolters, C. A. (1998). Self-regulated learning and college students' regulation of motivation. Journal of Educational Psychology, 9o(2), 224-235. https://doi.org/ 10.1037/0022-0663.90.2.224

Zimmerman, B. J. (2000). Attaining Self-Regulation: A Social Cognitive Perspective. In M. Boekaerts, P. R. Pintrich, \& M. Zeidner (Eds.), Handbook of self-regulation (pp. 13-39). San Diego, USA: Academic Press. 
Zimmerman, B. J., \& Martínez-Pons, M. (1992). Perceptions of efficacy and strategy use in the self-regulation of learning. In D. H. Schunk, J. L. Meece (Eds.), Student perceptions in the classroom: Causes and consequences (pp. 185-207). Hillsdale, NJ: Erlbaum.

Zimmerman, B. J., Moylan, A., Hudesman, J., White, N., \& Flugman, B. (2011). Enhancing self-reflection and mathematics achievement of at-risk urban technical college students. Psychological Test and Assessment Modeling, 53(1), 108-127. 